\title{
Study of cardiovascular anomalies in perinatal autopsies
}

\author{
Shivshetty B.S. ${ }^{1}$, Arpitha.$K^{2, *}$, Megha Kamalapurkar ${ }^{3}$, Anitha A. $\mathbf{M}^{4}$, Anuradha G. Patil ${ }^{5}$ \\ ${ }^{\mathbf{1}}$ Assistant Professor, ${ }^{2}$ Resident, ${ }^{4}$ Associate Professor, ${ }^{5}$ Professor and HOD, Dept. of Pathology, M.R. Medical College, Gulbarga, \\ Karnataka, ${ }^{3}$ Gynecologist, Dept. of Gynecology, Devata Hospital, Karnataka, India
}

*Corresponding Author:

Email: arpitha5561@gmail.com

\begin{abstract}
Aim: The main objective of this study is to evaluate the spectrum of cardiac findings in perinatal autopsy population. Materials and Methods: Study done over a period of 2 years (June 2016-June 2018). Total 200 perinatal autopsies were performed. The present autopsy study was conducted in the department of Pathology in a tertiary care centre, over a period of two years.

All perinatal autopsies diagnosed as congenital heart disease carried out during the study period were included in the study. Detail clinical history regarding age of the mother, pregnancy complications, presenting complaints was taken. Thorough morphological examination of heart was carried out. The diagnosis of congenital heart disease was confirmed and the case was included in the study. Consent was taken from ethical committee of the institute prior to commencement of study.

Results: Out of 200 perinatal autopsies 10 cases showed cardiac anomalies (Table 3), in which 6 cases were associated with other anomalies and remaining were isolated cases. All the cases were of intrauterine death (induced or spontaneous). Gestational age ranged between 12-40 weeks (Table 1). Weight of the foetuses ranged between 500g-2000g (Table 2). 10 different anomalies were noted in this study.

Conclusion: Fetal and pediatric cardiac autopsies have a crucial role in the counseling of parents with regard to both the cause of death of their fetus or child and the implications of such findings for future pregnancies, as well as for quality assurance of antenatal screening programs and antemortem diagnostic procedures. Cardiac abnormalities are found in up to $35 \%$ of fetal autopsies, and only about $50 \%$ of those abnormalities can be detected antenatally.
\end{abstract}

Keywords: Perinatal, Autopsy, Hetrotaxy syndrome.

\section{Introduction}

The incidence of moderate to severe congenital heart defects is approximately 6 to 7 per 1000 live births, with much higher rates detected in fetal autopsy populations. ${ }^{1}$ Prenatal diagnosis of cardiac disease is difficult, especially at an early gestation, although rates and accuracy of diagnosis improve when the ultrasound scan is performed by a pediatric cardiologist. ${ }^{1}$

Examination of the heart and associated vessels is routinely performed in fetal autopsies. The spectrum of cardiac findings include isolated structural cardiac defects, complex congenital heart defects, abnormalities of situs, cardiomyopathies, and acquired heart disease. ${ }^{1}$

The prognosis of congenital cardiac anomalies is poor and they contribute significantly to infant mortality. Fetal and pediatric cardiac autopsies have a crucial role in the counseling of parents with regard to both the cause of death of their fetus or child and the implications of such findings for future pregnancies as well as for quality assurance of antenatal screening programs and antemortem diagnostic procedures. ${ }^{2}$ Cardiac abnormalities are found in up to $35 \%$ of fetal autopsies and only about $50 \%$ of those abnormalities can be detected antenatally. Prenatal diagnosis improves the outcome of fetuses with certain types of cardiac anomalies, with programmed delivery in tertiary centers. In cases of complex and severe malformations it offers the opportunity for counseling and timely termination of pregnancy. ${ }^{2}$
Few studies have evaluated cardiac anomalies in fetal postmortem examinations. The main objective of this study is to evaluate the spectrum of cardiac findings in our fetal autopsy population.

\section{Materials and Methods}

Study done over a period of 2 years (June 2016 May 2018). Total 200 perinatal autopsies were performed. The present autopsy study was conducted in the department of

Pathology in a tertiary care centre, over a period of two years.

All perinatal autopsies diagnosed as congenital heart disease carried out during the study period were included in the study. Detail clinical history regarding age of the mother, pregnancy complications, presenting complaints was taken. Thorough morphological examination of heart was carried out. The diagnosis of congenital heart disease was confirmed and the case was included in the study. Consent was taken from ethical committee of the institute prior to commencement of study.

\section{Results}

Out of 200 perinatal autopsies 10 cases showed cardiac anomalies (Table 3), in which 6 cases were associated with other anomalies and remaining were isolated cases. All the cases were of intrauterine death (induced or spontaneous). Gestational age ranged between 12-40 weeks (Table 1). Weight of the foetuses 
ranged between 500g-2000g (Table 2). 10 different anomalies were noted in this study (Table 3 ).

First case with dextrocardia associated with heterotaxy syndrome showed apex of the heart on right side (dextrocardia), trilobed lungs on both sides, eparterial bronchi, cardia showing bilateral identical atrial appendages, dilated right ventricle, hypoplastic left ventricle and mitral stenosis on opening thoracic cavity. On opening abdominal cavity there was posterior and central stomach, asplenia and liver noted in centre (Fig. 1).

Second case showed aorta originating anteriorly from the normally positioned right ventricle and pulmonary artery arised posteriorly from the normally positioned morphological left ventricle and had fibrous continuity with the anterior mitral valve. It was a case of transposition of great arteries.

Third case showed narrow aorta, dilated pulmonary artery, VSD noted, dilated right atrium and ventricle, left ventricular cavity was absent. This was a case of hypoplastic left heart syndrome with VSD.

Fourth case showed narrow pulmonary artery, dilated aorta, dilated right atrium, low placed tricuspid valve and pointing towards apex of right ventricle. This case was associated with congenital cystic adenomatoid malformation.

Fifth case showed membranous VSD, right ventricular hypertrophy, pulmonary stenosis, overriding of aorta, ductus arterioses. This case $\mathrm{x}$-ray showed achondroplasia with short femur.

Sixth also showed transposition of great arteries with extralobar sequestration of lung (Fig. 2).

Seventh case showed overriding of aorta, right ventricular hypertrophy and pulmonary stenosis with absent ductus venoses. In this case the umbilical cord showed 2 vessels. (Fig. 3).

Eighth case showed sternal defect with ectopia cardis and VSD, diaphragmatic hernia, omphalocele with liver herniation, megacystis, imperforate anus. This is a case of pentology of Cantrell.

Ninth case showed situs inversus with dextrocardia and atrioventricular septal defect, double outlet right ventricle and megacystis (Fig. 4).

Last case showed acardiac fetus.

In the cases studied, majority of the lesions had septal defect followed by positioning defect, that is either blood vessels or the heart.
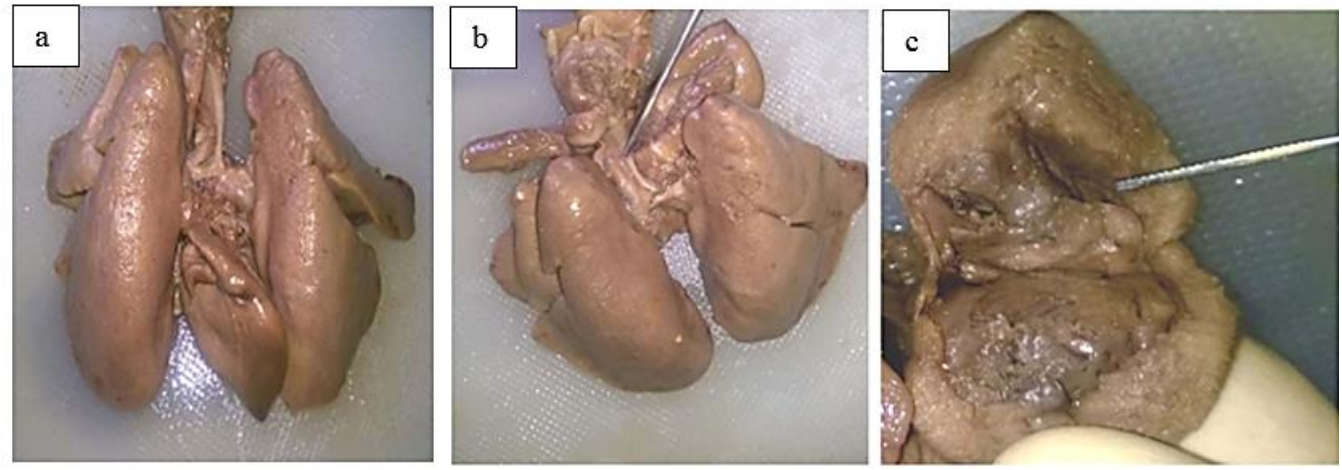

Fig. 1: Heterotazy syndrome; (a): Gross picture showing dextrocardia, central liver; (b) Bilateral trilobed lungs; (c): Eparterial bronchi; (d): Dilated right ventricle
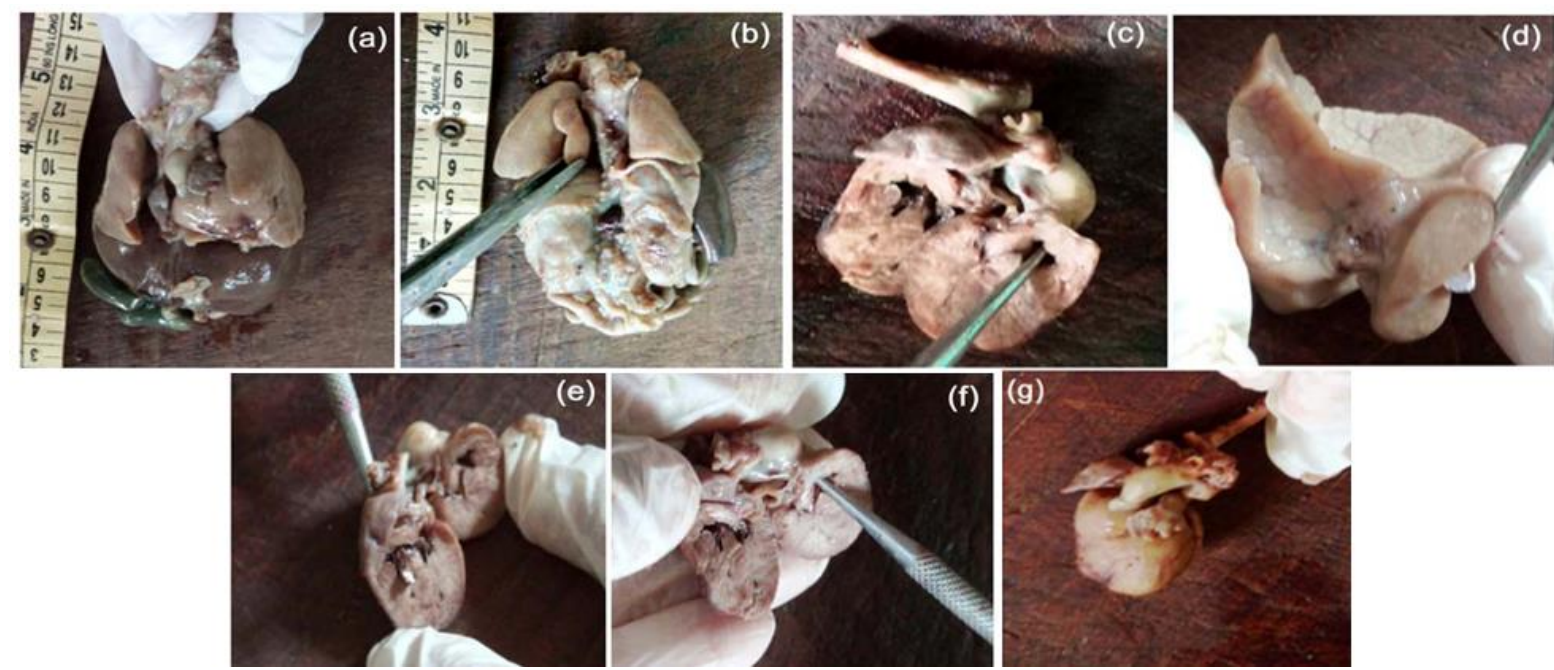

Fig. 2: TGA, (a): Enblock; (b \& d): Extralobal sequestration of lung; (c,e,f.g): TGA 
Table 1: Gestational age and number of cases with mode of death

\begin{tabular}{|l|c|c|}
\hline $\begin{array}{c}\text { Gestational age } \\
\text { (weeks) }\end{array}$ & No. of cases & $\begin{array}{c}\text { Mode of } \\
\text { death }\end{array}$ \\
\hline $1-12$ & 0 & IUD \\
\hline $12-24$ & 5 & IUD \\
\hline $24-40$ & 5 & IUD \\
\hline Total & 10 & \\
\hline
\end{tabular}

Table 2. Fetal weight and number of cases

\begin{tabular}{|l|c|}
\hline Weight (grams) & No. of cases \\
\hline $500-1000$ & 2 \\
\hline $1000-1500$ & 4 \\
\hline $1500-2000$ & 4 \\
\hline $2000-2500$ & - \\
\hline
\end{tabular}

Table 3: Cardiac and associated anomalies

\begin{tabular}{|l|c|c|}
\hline S. No. & Anomalies & Associated anomalies \\
\hline 1 & Dextrocardia with hypoplastic left ventricle & Heterotaxy syndrome \\
\hline 2 & Transposition of great arteries & Hypoplastic left heart syndrome \\
\hline 3 & Hypoplastic left heart with VSD & CCAM \\
\hline 4 & Ebstein's anomaly & Extralobar sequestration of lung \\
\hline 5 & Tetrology of Fallot & $\begin{array}{c}\text { Sternal defect, diaphragmatic } \\
\text { hernia,megacystis, omphalocele }\end{array}$ \\
\hline 6 & Transposition of great arteries & Megacystis \\
\hline 7 & Absent ductus venoses & \\
\hline 9 & Pentology of cantrell & Double outlet right ventricle, \\
\hline 10 & Acardia & \\
\hline
\end{tabular}
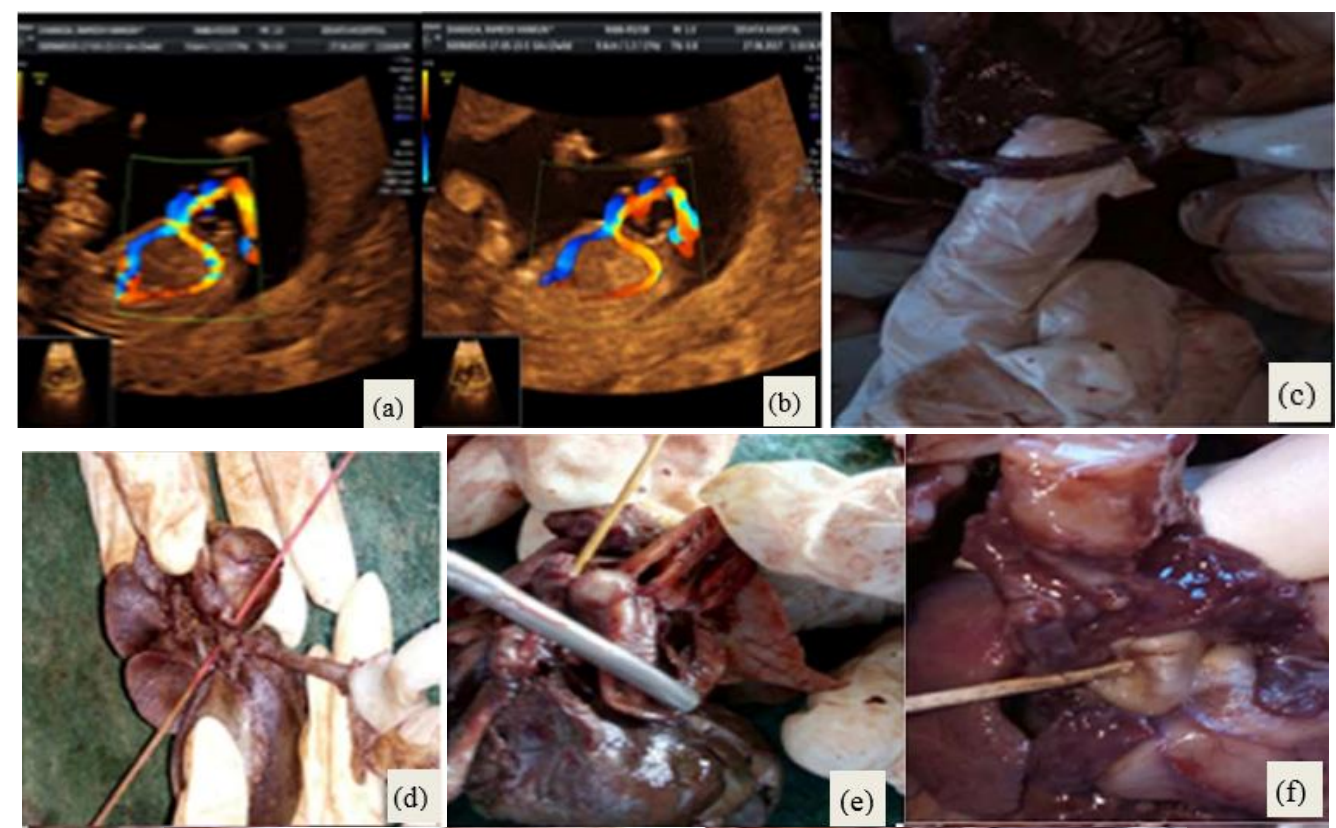

(b)

(c)

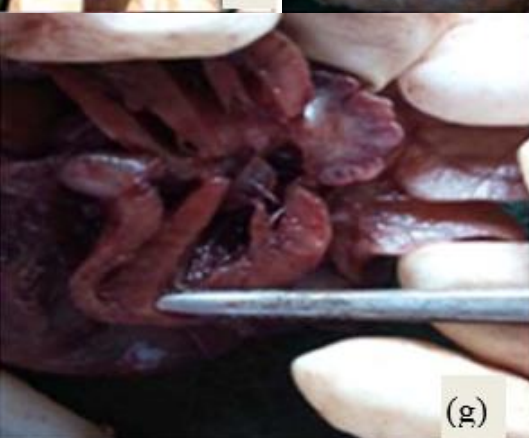

(e)
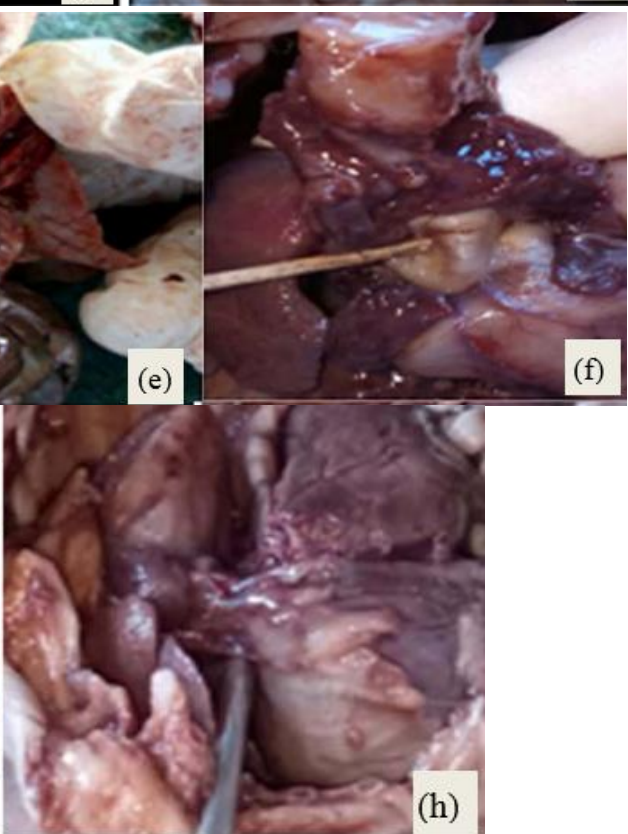

(f)

Fig. 3: Absent ductus arterioses; (a, b): Radiology images; (c, d): Patent ductus arterioses 


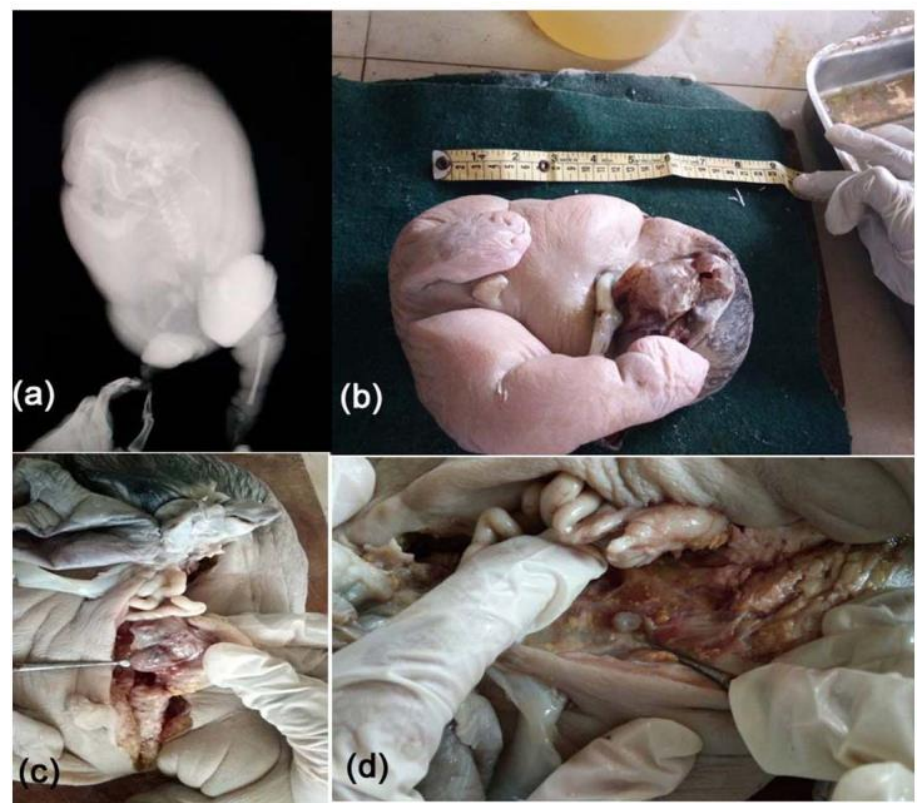

Fig. 4: Acardiac fetus; (a): X-ray of fetus; (b-d): Autopsy pictures

\section{Discussion}

Failure of normal lateralization results in abnormal bilateral symmetry of normally asymmetric viscera and duplication of either right- or left-sided structures. These conditions present with indeterminate situs or situs ambiguous and are often referred to as isomerism or heterotaxy syndromes. Heterotaxy syndromes are usually associated with congenital heart defects and splenic abnormalities. The major forms include asplenia or Ivemark's syndrome and polysplenia syndrome. ${ }^{4}$ In our study first case is a right isomerism with aspenia. Right isomerism is a spectrum of rare congenital anomalies such as complex cardiac malformations, asplenia, gut malrotation etc. resulting from abnormal laterality orientation, wherein patients rarely survive into adulthood. Early diagnosis is possible by imaging, especially chest MRI, owing to its better depiction of cardiovascular anatomy. ${ }^{5}$

Tetralogy of Fallot is a congenital cardiac malformation that consists of an interventricular communication, also known as a ventricular septal defect, obstruction of the right ventricular outflow tract, override of the ventricular septum by the aortic root, and right ventricular hypertrophy. This combination of lesions occurs in 3 of every 10,000 live births, and accounts for $7-10 \%$ of all congenital cardiac malformations. ${ }^{6}$

In transposition of the great arteries (TGA), each great vessel inappropriately arises from the opposite ventricle; that is, the aorta originates from the RV and the pulmonary artery originates from the LV. This anomaly accounts for approximately $7 \%$ of congenital heart defects, affecting 40 of 100,000 live births. ${ }^{7}$

Absent ductus venoses is a rare anomaly with a prevalence of 1 in 2532, in which the umbilical vein connection to the venous system may be extrahepatic, by passing the liver or intrahepatic via the portal venous system. ADV itself is significantly associated with fetal cardiac and extracardiac anomalies, aneuploidies and hydrops, independent of the type of umbilical venous drainage. ${ }^{8,9}$

Hypoplastic left heart syndrome (HLHS) is a complex combination of cardiac malformations that probably results from multiple developmental errors in the early stages of cardiogenesis and that, if left untreated, invariably proves fatal. ${ }^{10}$

Cantrell's pentalogy $(\mathrm{CP})$, a rare congenital malformation, consists of the supraumbilical abdominal wall defect, the sterna lower part defect and agenesis of the anterior portion of the diaphragm, an absence of the diaphragmatic part of the pericardium, and a malformation of cardia.

It has a reported prevalence of 0.2 per 1,000 live births and occurs twice as often in boys as in girlsPrevalence is 1 per 65000 live births \& classified as a developmental defect of midline anterior body wall. ${ }^{11}$

Situs inversus is a short form of the Latin phrase "Situs inversus Viscerum" meaning "inverted position of the internal organs, as first described by Marco Severino in 1643. The incidence is about 1:10,000 live people. Normal human development results in an asymmetrical arrangement of the organs within the chest and abdomen. Typically, the heart lies on the left side of the body (levocardia), the liver and spleen lie on the right. It accounts for 1-3\% of congenital cardiac defects. In this the aorta and PA arise mainly from the RV without mitral—aortic valve fibrous continuity. A double infundibulum is usually present. It is almost always associated with a VSD. The VSD may be subaortic, subpulmonary, doubly committed (aorta and pulmonary artery), or noncommitted. ${ }^{12}$ 
Acardiac twinning, one of the most severe congenital malformations seen in humans, is unique to monochorionic placentation and occurs with a reported prevalence of $1 \%$ of monozygotic twins. The incidence of acardiac twinning has been quoted as 1 in 34,600 deliveries. There is a female predominance in acardiac twins and their normal twin counterparts. ${ }^{13}$

\section{References}

1. Elena k. Grant and Margaret J. Evans cardiac findings in fetal and pediatric autopsies: a five-year retrospective review. Pediatric and Developmental Pathology. 2009;12:103-110.

2. Andrew M. Taylor \& Owen J. Arthurs. Postmortem cardiac imaging in fetuses and children. Pediatr Radiol. 2015;45:549-555.

3. Carla Ramalho, Otı'lia Branda, Jose' Monterroso, Alexandra Matias, Nuno Montenegr. Cardiac findings in routine fetal autopsies: more than meets the eye? 2012;163:142-147.

4. Himanshu Agarwal, Shireesh Kumar Mittal, Chaitanya D Kulkarni, Ashok Kumar Verma, Saurabh Kumar Srivastava. Right isomerism with complex cardiac anomalies presenting with dysphagia - A case report. 2011;5(4):1-9.

5. Sudhin Thayyil, Jon O Cleary, Neil J Sebire, Rosemary J Scott, Kling Chong, Roxanna Gunny, Catherine M Owens, Oystein E Olsen, Amaka C Offi ah, Harold G Parks, Lyn S Chitty, Anthony N Price, Tarek A Yousry, Nicola J Robertson, Mark F Lythgoe, Andrew M Taylor. Post-mortem examination of human fetuses: a comparison of whole-body high-field MRI at $9.4 \mathrm{~T}$ with conventional MRI and invasive autopsy. Vol 374 August $8,2009$.
6. Frederique Bailliard and Robert H Anderson. Tetralogy of Fallot. Orphanet Journal of Rare Diseases. 2009, 4:2.

7. Reda $m$. Shahercomplete and inverted transposition of the great Vessels. British Heart journal. 1964, 26, 51.

8. Smith J. Absence of the ductus venosus: a case report reseachonline@jcu volume 4 issue 42008.

9. Netam SS, Kumar S, Gupta S, Jain V, Singh R, Tiwari S. Absent ductus venosus with single umbilical artery: a rare association. $J$ of Evolution of Med and Dent Sci. 2015;4(33).

10. Amir Hossein Jafarian, Abbas Ali Omidia, Alireza Fazelb, Hamed Sadeghiana, Bahareh Joushan, Pentalogy of Cantrell: a case report. JRMS. January 2011; Vol 16, No 1.

11. Khiste, J. A., Gadgil, P. A., Pandit, G. A., Halgale, M. J. and Moon, P. C. disease. International Journal of Current Research, 8;(03)28508-28510.

12. Subha Ghosh, Gail Yarmish, Alla Godelman, Linda B. Haramati, Hugo Spindola-Franco. Anomalies of Visceroatrial Situs. AJR: 193, October 2009.

13. Godse A, Hosie G. Acardiacus acephalus twinning associated with exomphalos major, high impeforate anus and hypospadias. Case Rep Perinat Med. 2014;3(1):7981.

How to cite this article: Shivshetty BS, Arpitha K, Kamalapurkar M, Anitha AM, Patil AG. Study of cardiovascular anomalies in perinatal autopsies. J Diagn Pathol Oncol. 2018;4(3):155-159. 